\title{
In justice we trust: A model of the role of trust in the organization in applicant reactions to the selection process
}

\author{
Anthony Celani ${ }^{\text {a,* }}$, Sabrina Deutsch-Salamon ${ }^{\mathrm{b}, 1}$, Parbudyal Singh ${ }^{\mathrm{b}, 2}$ \\ a DeGroote School of Business, McMaster University, 1280 Main Street West, Hamilton, Ontario, Canada L8S 4M4 \\ b School of Administrative Studies, York University, 4700 Keele Street, Toronto, Ontario, Canada M3J 1P3
}

A R T I C L E I N F O

\section{Keywords:}

Selection

Applicant reactions

Trust

Justice

\begin{abstract}
A B S T R A C T
Despite the reliance on organizational justice in applicant reactions research, and the research attention devoted to the relationship between organizational justice and organizational trust (Brockner, J., \& Siegel, P. (1996). Understanding the interaction between procedural and distributive justice: The role of trust. In R. Kramer, \& T. Tyler (Eds.), Trust in organizations: Frontiers of theory and research (pp. 390-413). Thousand Oaks, CA: Sage; Lewicki, R.J., Wiethoff, C., \& Tomlinson, E. C. (2005). What is the role of trust in organizational justice? In J. Greenberg, \& J. A. Colquitt (Eds.), Handbook of Organizational Justice (pp. 247-270). Mahwah, New Jersey: Lawrence Erlbaum Associates), to date little, if any, attention has been directed to combining organizational justice and organizational trust perspectives in applicant reactions research. In this paper, we first review extant applicant reactions literature which has been based on the organizational justice literature. We then develop a model that integrates organizational justice and trust perspectives to better understand the processes underlying applicant reactions across different stages of the selection process. We explain how the propositions derived from this model can inform future research on applicant reactions to selection procedures.
\end{abstract}

\section{Introduction}

Questions concerning applicant reactions to employee selection processes have generated a great deal of research attention over the last fifteen years (Arvey \& Sackett, 1993; Gilliand, 1993; Hausknecht, Day \& Thomas, 2004; Ployhart, McFarland \& Ryan, 2003; Ryan \& Ployhart, 2000; Ryan \& Tippins, 2004; Viswesvaran \& Ones, 2004). As Ryan and Ployhart (2000: 566) state, applicant reactions research is a significant area of study for organizations because "the basic premise of research on applicant perceptions of selection processes and procedures has been that these perceptions affect how the applicant views the organization, his or her decision to join the organization, and subsequent behaviors." Understanding applicant perceptions of the selection process might therefore enhance the capacity to affect those perceptions and related applicant attitudes and behavior. Such attitudes and behaviors can take many forms (Hausknecht et al., 2004). For instance, an organization can lose top candidates if the selection process is seen as invasive or unfair; applicants with negative reactions may discourage other applicants from working with the organization; and, applicants who perceive injustice in the selection process may not re-apply to the organization or may not buy its products or services.

Organizational justice theory has been the dominant approach used in applicant reactions research to date. The basic premise of organizational justice theory in selection contexts is that applicants view selection procedures in terms of justice, and that these

\footnotetext{
* Corresponding author. Tel.: +1 905525 9140x26167; fax: +1 9055231991.

E-mail addresses: celania@mcmaster.ca (A. Celani), sdeutsch@yorku.ca (S. Deutsch-Salamon), singhp@yorku.ca (P. Singh).

1 Tel.: +1 $4167362100 \times 70844$; fax: +1 4167365963 .

2 Tel.: +1 416736 2100x30100; fax: +1 4167365963.
} 
perceptions influence future attitudes, intentions, self-perceptions, and behaviors (e.g., Gilliand, 1993; Hausknecht et al., 2004). The first goal of this paper is to review the applicant reactions literature that has been accumulating since the early 1990 s and provide clarity on what we know about determinants of applicant responses to date.

The second goal of this paper is to enhance our understanding of applicant reactions by considering the critical role of applicant trust in the organization in shaping their experience and responses. While we agree that a justice perspective is adequate and useful in examining applicant reactions, we propose that considerable insight can be gained by integrating an organizational trust perspective to this line of examination. Indeed, while prior research attests that perceptions of fairness depend heavily on the level of trust (e.g. Fulk, Brief, \& Barr, 1985), and that justice perceptions influence consequent trust in the organization (Brockner \& Siegel, 1996; Lewicki, Wiethoff, \& Tomlinson, 2005), to date, little, if any, attention has been directed to the dynamic relationship between organizational justice and trust in influencing applicant reactions.

The model developed in this paper integrates organizational justice and trust perspectives, thus offering insight into the process underlying applicant reactions across different stages of the selection process. Most importantly, this model takes into account that applicants approach the selection process with a given level of initial trust in the organization, which is likely to color applicant experiences and influence their responses to the selection process. Specifically, initial trust in the organization is likely to affect applicant evaluations of the fairness of the selection process, as well as influence how they respond to these fairness evaluations. This model then sheds light on two important but neglected areas of applicant reactions research - how different applicant perceptions are related, and how they change over the course of the selection process.

\section{A review of the theoretical and empirical literature on organizational justice in applicant reactions research}

The application of organizational justice theory in applicant reactions research provides valuable insights into how individuals respond to selection procedures. While organizational justice theorists have defined justice along the four predominant dimensions, viz., procedural justice, distributive justice, interpersonal, and informational justice (Gilliland \& Hale, 2005), we will focus on procedural and distributive justice since a classification of justice into these two dimensions has dominated applicant reactions research. It should be noted that, as explained below, in this two-dimensional classification, informational and interpersonal justice are included under procedural justice. The application of organizational justice theory in applicant reactions research by Schmitt and Gilliland (1992), Gilliland (1993), Arvey and Sackett (1993), and Smither, Reilly, Millsap, Perlman, and Stoffey (1993) are regarded as seminal pieces in this line of inquiry (Ryan \& Ployhart, 2000).

Fig. 1, a schematic representation of the literature, captures the key variables in the research on organizational justice on applicant reactions. Essentially, selection procedures affect both procedural justice (and the ten sub-rules) and distributive justice (and the three sub-rules); this relationship is moderated by other factors, including test types, incumbent versus applicant perceptions, racial differences, privacy concerns and technology. Perceptions of organizational justice affect attitudinal and behavioral outcomes in turn ${ }^{3}$. We will explain each variable and the related relationships in the following sections.

\subsection{Procedural justice}

Procedural justice focuses on the perceived fairness of the procedures that are used in a decision-making process (Folger \& Greenberg, 1985). Greenberg further defined procedural justice according to two other factors, "specifically, the validity of the information provided as the basis for decision-making... and the interpersonal sensitivity shown regarding the personal effects of the decision...indeed, these factors are closely related to several rules of procedural fairness" (1993: 83). The procedural justice construct used in Gilliland's (1993) seminal model relating to selection systems is based on research by Leventhal (1980) that defined procedural justice in terms of the fulfillment or violation of ten procedural justice rules, classified into three broad categories. First, there are formal characteristics of the selection system that cover four rules: job relatedness, opportunity to perform, opportunity for reconsideration, and consistency of administration. The second category, viz., explanation or information offered to applicants covers three rules: feedback, selection information, and honesty in treatment. The final category - the interpersonal treatment of applicants - covers the three remaining rules: interpersonal effectiveness of the administrator, twoway communication, and propriety of questions (Gilliland, 1993).

The majority of applicant reactions research has focused on the application of Gilliland's (1993) ten procedural justice rules, viz., job relatedness, opportunity to perform, consistency bias, ease of faking, feedback, selection information, honesty, interpersonal effectiveness, two-way communication, and question propriety. Relatively less research attention has been given to the distributive justice aspects of Gilliland's (1993) model. Research has shown support for the association between Gilliland's (1993) procedural justice rules and applicant attitudes regarding the fairness of selection procedures (Ployhart, Ryan, \& Bennett, 1999). Gilliland and Honig (1994) conclude that the ten procedural justice rules explain $50 \%$ of applicants' overall perceptions of procedural fairness. Below, we review the literature on the ten rules, categorized into three broad groups.

\footnotetext{
${ }^{3}$ We do not dedicate a distinct section in the paper on attitudinal and behavioral outcomes of organizational justice, as this is integrated in the discussion throughout the paper. In summary, in terms of the direct effects of justice perceptions on applicant outcomes, a meta-analysis by Hausknecht et al., 2004) found positive associations between procedural justice characteristics and applicant perceptions. Positive associations were also found between applicant perceptions and applicant outcomes such as actual and perceived performance, organizational attractiveness, recommendation intentions, offer acceptance intentions, selfefficacy, and self-esteem.
} 


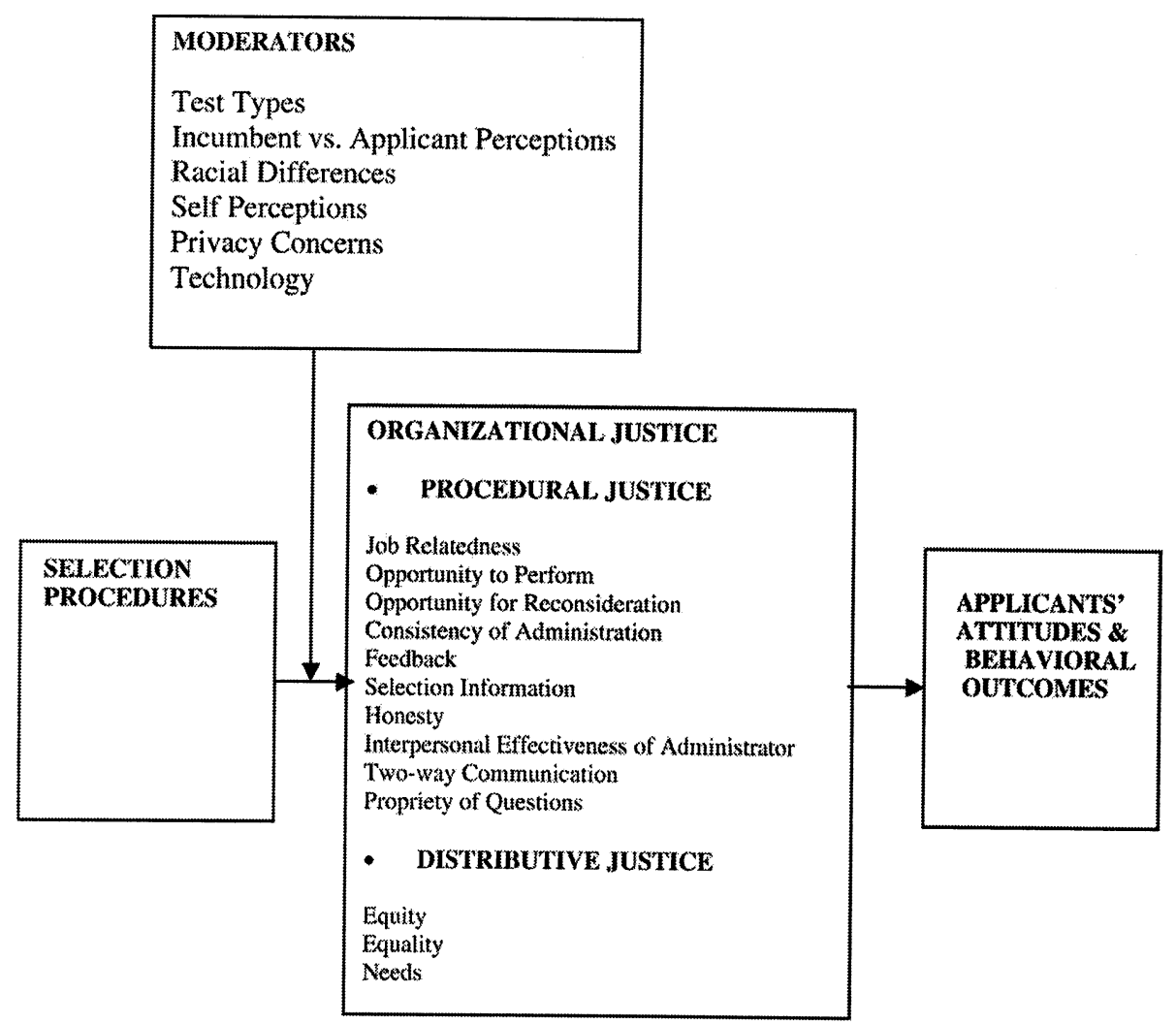

Fig. 1. Applicant reactions to organizational selection procedures: A schematic representation of the literature.

\subsubsection{Formal characteristics of the selection process}

2.1.1.1. Job relatedness. Of all factors in Gilliland's (1993) model, job relatedness has received the strongest research support (Ambrose, 2000; Chambers, 2002; Elkin \& Phillip, 2000; Gilliland \& Chan, 2001; Kravitz, Stinson \& Chavez, 1996; Lievens, De Corte \& Brysse, 2003). Job relatedness was originally defined by Gilliland as one factor that referred to "the extent to which a test either appears to measure content relevant to the job or appears to be valid" (1993: 703). In the development of a measure of Gilliland's procedural justice rules, Bauer et al. (2001) found that job relatedness represented two factors containing content validity and predictive validity components. However, Hausknecht et al. (2004) points out that job relatedness is often conceptualized as a twofactor construct comprised of face validity and perceived predictive validity. Face validity applies to an assessment of content validity from a test taker's perspective rather than from a test maker's perspective, and perceived predictive validity involves an individual's assessment of whether a selection procedure can predict job performance (Gatewood \& Field, 1998; Hausknecht et al., 2004; Smither et al., 1993). Empirical research has demonstrated that test test-taker perceptions of face and predictive validity are not only different in nature, but also highly correlated with their perceptions of the procedural fairness of such tests (Ryan \& Chan 1999; Truxillo, Bauer, \& Sanchez 2001). Research conducted by Steiner and Gilliland (1996) involving student evaluations of selection procedures revealed that face validity was important in determining whether they reacted favorably to selection procedures.

Furthermore, a significant body of research has confirmed that test takers react more positively to a psychological instrument when face validity is apparent, and more negatively when they cannot authenticate job relevance (Cropanzano \& Wright, 2003). Research also shows that test takers also react positively to selection procedures that reflect actual job duties, including work samples (Kravitz et al., 1996), and assessment centres (Macan, Avedon, Paese, \& Smith, 1994). Carless (2006) used Gilliland's organizational justice framework to examine the perceptions of individuals applying to a police force in Australia. According to Carless (2006), interviews and physical agility tests received more positive reactions than psychological tests. Furthermore, it was found that such fairness perceptions were largely influenced by initial applicant beliefs concerning the selection tests in question.

2.1.1.2. Opportunity to perform. Emanating from the organizational justice literature, opportunity to perform reflects Thibaut and Walker's (1975) concept of voice where greater procedural justice is deemed to have been served when individuals involved in a decision process are given the opportunity to provide input. The opportunity to perform is not only seen as important (Truxillo et al., 2001) in a North American context, but also cross-culturally (Steiner \& Gilliland, 2001). Singer (1990) identified two items that comprise this factor: chance for the applicant to make a case for himself/herself in the selection process and sufficient time for interviews. Gilliland (1993:704) contends that in the selection domain, voice can be interpreted as having "adequate opportunity 
to demonstrate one's knowledge, skills, and abilities in the testing situation or the possibility of exerting control in a selection situation." Research has indicated that some selection tests provide more opportunity to perform than others. For example, research by Latham and Finnegan (1993), and Schuler (1993) suggests that applicants may prefer an unstructured interview over a structured interview because it is perceived as providing more opportunity to perform. Research has also identified a phenomenon, where applicants react negatively to selection procedures that are highly valid, known as the justice dilemma (Cropanzano \& Wright, 2003; Folger \& Cropanzano, 1998). It has been suggested that such a dilemma may be resolved through the use of additional selection procedures in conjunction with the original procedure in order to provide applicants with more opportunity to perform (Cropanzano \& Wright, 2003; Rosse, Miller, \& Stecher, 1994).

2.1.1.3. Reconsideration opportunity. Distinct from opportunity to perform, reconsideration opportunity provides an individual in a selection context with a second chance to influence the selection decision. Arvey and Sackett (1993) also argue for the importance of the relationship between reconsideration opportunity and justice perceptions. The research on this factor reflects different findings with respect to applicant fairness perceptions. In a field study conducted by Gilliland (1994), job applicants were generally not concerned about reconsideration opportunities in the selection process. However, reconsideration opportunities were of great concern among job applicants vying for a promotional opportunity (McEnrue, 1989). The importance of reconsideration opportunity was also found to be inconclusive between selection tests within the same selection procedure (Truxillo et al., 2001).

2.1.1.4. Consistency of administration. This factor refers to the standardization of the decision-making process for all applicants involved in the selection procedure. The particular aspects of the selection process in which consistency should be applied are in the delivery of the test content, and in the scoring and interpretation of the results of the applicants (Gilliland, 1993). Individuals prefer that assessment processes are consistent. Inconsistent processes open up a host of possibilities for bias and error-prone decision-making (Cropanzano \& Wright, 2003). Empirical research has demonstrated that factors such as equal time allotment for test-taking (Ployhart \& Ryan, 1997; Ryan, Greguras, \& Ployhart 1996), and the administration of identical selection procedures (Singer, 1990) can be important factors influencing applicants' justice perceptions.

\subsubsection{Informational justice: information offered to applicants about the selection process}

2.1.2.1. Feedback. Gilliland (1993) describes feedback as representing two dimensions of measurement: timeliness of feedback, and 'informativeness' of the feedback given. This not only applies to particular testing situations, but also to the speed and insightful nature of the feedback given regarding the selection process in general. Research by Liden and Parsons (1986), and Lounsbury, Bobrow and Jensen (1989) indicates that applicants prefer selection procedures that provide feedback over those that do not. Research by Gilliland et al. (2001) demonstrates that applicants also prefer timely feedback. Specifically, research by Rynes, Bretz and Gerhart (1991) and Gilliland (1995) reveals that delays in information received by applicants are looked upon negatively, and serve as a factor influencing negative applicant fairness perceptions. However, providing explanations for such delays may help to lessen the degree to which applicants experience negative justice perceptions (Truxillo, Bauer, Campion \& Paronto, 2002).

2.1.2.2. Selection information. Selection information refers to the offering of various types of information to candidates at various stages of a selection process. This has been found to have an effect on perceptions of fairness (Horvath, Ryan \& Steirwalt, 2000; Truxillo, Steiner \& Gilliland, 2004). Common information that is offered includes descriptions about a selection procedure. "In terms of explanation or justification for a selection procedure, perceptions of fairness are likely to be influenced by information on the validity of the selection process, information on scoring and the way in which scores are used in decision-making, and justification for a particular selection decision"(Gilliland, 1993: 706). Advance notice of selection procedures also contributes to applicant perceptions of increased fairness (Bauer, Maertz, Dolen, \& Campion, 1998; Truxillo et al., 2004). The content of selection decision explanations also serves as a form of selection information that can affect an applicant's perceptions of procedural fairness (Ployhart, Ryan, \& Bennett, 1999). Research on selection information has revealed that applicant reactions can result from complex interactions of many factors that include the type of explanation, and the self-efficacy of the applicant (Horvath, Ryan, \& Steirwalt, 2000).

2.1.2.3. Honesty. The honesty factor describes the truthfulness of the communication delivered to an individual involved in a selection process. In spite of the apparent overlap among the factors of honesty, selection information, and feedback, research has demonstrated that honesty is an independent factor when assessing procedural justice in a selection context (Bauer et al., 2001). Not surprisingly, research has demonstrated that dishonesty creates negative reactions among individuals in a selection context (Bies \& Moag, 1986; Schmitt \& Coyle, 1976; Singer, 1990). However, research conducted by Bies and Shapiro (1988) found that apologies for dishonesty can serve to mitigate the perceived injustice experienced by applicants in the selection process.

\subsubsection{Interpersonal justice - interpersonal treatment of applicants during the selection process}

2.1.3.1. Interpersonal effectiveness of administrator. This factor refers to the extent to which applicants are treated sympathetically (Gilliland \& Hale, 2005). Recruitment interviews are a common context in which this factor is examined. Research has suggested that recruiter behaviors and personalities are significant factors that affect applicant reactions to selection procedures (Rynes, 1993). It has also been suggested that "applicants have a preference for interviewers who are attentive, socially perceptive, warm, thoughtful and likeable in their conduct of the interview"(Harris, 2000: 153). In fact, research by Liden and Parsons (1986), and 
Schmitt and Coyle (1976) demonstrate that poor applicant opinions of the organization reflected the use of an interviewer who was believed to be less personable. Harris and Fink (1987) found a significant association between recruiter characteristics and applicant job perceptions.

2.1.3.2. Two-way communication. This form of communication is more interpersonal in nature than the opportunity to perform factor (Ryan \& Ployhart, 2000). It describes the extent to which individuals within a selection context are given the opportunity to have their opinions considered. "Two-way communication also can refer to the opportunity to ask questions regarding the job, the organization, or even the selection process. The selection system must provide applicants with adequate opportunity to gain information that is relevant to making acceptance decisions. If such opportunities are not found, applicants' satisfaction with the selection process will be lessened"(Gilliland, 1993: 708). In the context of the selection interview, researchers have suggested that the use of structured interviews in conjunction with unstructured interviews may best balance an applicant's opportunity to engage in two-way communication while assuring that the hiring organization applies a selection procedure that addresses its validity concerns (Barber 1998; Folger \& Compranzano, 1998; Kohn \& Dipboye, 1998; Werbel \& Gilliland, 1999).

2.1.3.3. Propriety of questions. Two dimensions to consider within this factor include improper questioning, and the use of prejudicial statements (Bauer et al., 2001). Saks, Lek, and Saunders (1995) found that discriminatory questions negatively influenced justice perceptions. A literature review conducted by Cropanzano and Wright (2003: 17) reveals that "test takers often feel that certain questions simply should not be allowed, at least not without an adequate justification. For example, some items may be seen as invasive and a violation of a person's right to privacy. When violations occur, evidence indicates that test takers are likely to react quite poorly to the assessment process." Using hypothetical interviews, Saks and McCarthy (2006) examined applicant reactions to the use of discriminatory interview questions. A significant negative association was found between the use of discriminatory questions and applicant perceptions regarding the interview, the interviewer, employee treatment, employment intentions, job offer acceptance, and recommendation intentions. Wallace, Page, and Lippstreu (2006) investigated applicant reactions to both legally advisable and legally problematic application blanks. The researchers found that when compared to applicants completing the legally advisable application blank, applicants completing the legally problematic application blank had lower justice perceptions and higher litigation intentions.

\subsection{Distributive justice}

Distributive justice is defined as the perceived fairness of outcomes (e.g., Homans, 1961). In a selection context, the hiring decision is the outcome that is addressed when evaluating distributive justice. Thus, whether or not one receives a favorable outcome (hired or not) is seen as a major influence. Overall, and as expected, accepted applicants react more favorably than those who are rejected (Elkin \& Phillip, 2000; Smither, Reilly, Millsap, Perlman \& Stoffey, 1993). Bauer et al. (1998) found that outcome favorability was linked to organizational attractiveness, intentions toward the organization, and general testing fairness. Cunningham (1989) found that applicants who were not recommended for positions were more likely to minimize the importance of the test used in the hiring decision, believing that they could 'outguess' the test. Robertson, Iles, Gratton, and Sharpley (1991) reported that applicants who were successful in a selection process consisting of a situational interview and an assessment centre displayed greater organizational commitment.

As with procedural justice, Gilliland's (1993) model measures distributive justice in terms of rule violations. The three factors representing these rules of distributive justice include: equity, equality, and needs. Comparatively, research on distributive justice factors has received less research attention (Gilliland \& Chan, 2001). In what follows, we discuss the three factors influencing distributive justice in the applicant reactions literature.

\subsubsection{Equity}

Of all distributive justice rules, the equity rule has received the most research attention (Gilliland \& Chan, 2001). Researchers have advanced the general notion that organizations using an equity principle in its decision-making processes will be seen as demonstrating justice throughout its entire organization (Beirhof, Buck, \& Klein, 1986; Deutsch, 1975). The equity rule was originally advocated by Adams (1965) as a means to determine the fairness of an outcome. Essentially, equity theory posits that people are not so much concerned about the absolute level of outcomes per se but whether those outcomes were fair when compared with a referent other (Adams, 1965; Colquitt, Conlon, Wesson, Porter, Yee Ng, 2001). Gilliland (1993) describes three potential referents that may be used by applicants within a selection context: other applicants, structural aspects of the system such as employment contracts, and self-referents. "The use of a self-referent in forming equity perceptions translates into an evaluation of met expectations. Based on one's past qualifications, one's past success at attaining a job, and one's current qualifications, an expectation is formed regarding the likelihood that the job will be attained" (Gilliland, 1993: 716). The equity rule in a selection context has received empirical support and as Gilliland (1994: 698) states, "justice theories and the current results indicate that distributive fairness, which included items regarding outcome satisfaction, was higher among those who expected to get the job than among those who did not expect to get the job."

\subsubsection{Equality}

When applied to a selection context, equality suggests that all individuals competing for a job should have an equal chance of obtaining that job on the basis of job relevant characteristics (Anderson, Born, Cunningham-Snell, 2001). Violations of the equality 
rule can result in negative applicant justice perceptions. Although such effects have been found cross-culturally (Steiner $\&$ Gilliland, 2001), generally, "the effects of the salience of equality rules on perceptions of fairness have not been systematically examined by researchers" (Gilliland \& Hale, 2005: 428).

\subsubsection{Needs}

The needs rule of distributive justice suggests that outcomes should be distributed to individuals according to their needs. An often cited example is the accommodation of individuals with special needs. Empirical research conducted by Truxillo and Bauer found that "race and the belief that banding is associated with affirmative action interacted to affect fairness perceptions and outcomes variables" (1999: 334). As with the equality rule, the needs rule has not received much research attention to date, but may become a topic of greater study in the near future due to the increasing racial, ethnic, and cultural diversity of workforces around the world.

\subsection{Other applicant reactions research: possible moderators}

In the context of Gilliland's (1993) model, the construct of organizational justice is represented by rules whose violation can create negative applicant reactions to selection procedures. This model has been the basis of much applicant reactions research since its inception. In general, laboratory and field research has provided strong support for this model (Gilliland \& Chan, 2001). However, other applicant reactions research has focused on test-taker attitudes as an influence on how applicants respond to the selection process (Ryan \& Ployhart, 2000). This research to date has attempted to identify what determines what an applicant might think or feel as a participant during the selection process, and includes such variables as test types, incumbent versus applicant perceptions, racial differences, privacy concerns, and technology.

\subsubsection{Tests types}

In a comparison between video-based and paper-and-pencil based tests Chan and Schmitt (1997) found that face validity perceptions are significantly higher when the test is administered in the video-based method than when administered in the paper-and-pencil method. Similarly, Motowildo, Dunnette and Carter (1990) found that video-based situational tests have higher perceptions of face validity, and the testing method was considered more appropriate. Vianen, Taris, Scholten and Schinkel (2004) reported that selection tests differed in applicant perceptions of job relatedness; for instance, situational judgment tests were rated higher versus cognitive ability and personality tests.

With respect to physical ability tests, Ryan et al. (1996) found considerable variation in applicant reactions to different types of physical ability tests. The job which applicants seek serves as a factor that influences applicant perceptions of the type of test used during a selection process. Ryan, Greguras and Ployhart (1996) had earlier reported in a study of firefighters reactions to various physical ability tests that simulation and common physical ability tests were perceived to be more job-related than non-physical ability tests. On the other hand, cognitive ability tests were perceived less favorably by applicants than interviews and work sample tests. In other studies, cognitive ability tests were perceived more favorably than personality tests (Chan, Schmitt, Sacco \& DeShon, 1998; Steiner \& Gilliland, 1996; Thorsteinson \& Ryan, 1997).

Murphy, Thornton and Prue (1991) found that judgments of the acceptability of employee drug testing are significantly linked to characteristics of the job in question. However, it has been found that the adherence to other justice rules in the selection process may mitigate applicants' negative fairness perceptions of drug testing (Cropanzano \& Konovsky, 1995).

\subsubsection{Incumbent versus applicant perceptions}

The current research, although sparse, is leading researchers to believe that differences do exist between incumbent and applicant perceptions of selection processes. While reactions to promotional procedures deal with members of the organization, hiring decisions deal with individuals outside the organization. Thus, researchers "...might expect different mechanisms underlying attitude formation" (Ryan \& Ployhart, 2000).

\subsubsection{Racial differences}

Research by Chan (1997) and Chan and Schmitt (1997) have found that racial differences in perceptions can exist; however, the formation of those perceptions is dependent upon the type of test used in the selection process. Such differences were supported to a small degree by Schmit and Ryan (1997) when comparing African-American and Caucasian applicants - Caucasians had higher test-taking motivation, believed more in the efficacy of tests, and had less test anxiety. Research has also examined racial differences in test test-taking motivation, and test performance. Research initially conducted by Arvey, Strickland, Drauden and Martin (1990) found some support for racial differences in test test-taking motivation and test performance. Chan, Schmitt, DeShon, Clause, and Delbridge (1997) also found Black-White difference in test performance is in part due to a Black-White difference in test test-taking motivation. However, other research suggests that there is no evidence that there were differential race effects relating belief in test, test responses, and test performance (Chan, et al., 1998: 482). Finally, McMillan-Capehart and Orlando (2005) found that applicants considered hiring decisions to be less fair when organizations tied their decisions to affirmative action.

\subsubsection{Self-perceptions}

Ployhart and Ryan (1997) found that applicants who perceived selection procedures to be fair had higher self-efficacy whether they were accepted or not, but experienced lower self-efficacy if they were selected under unfair procedures. Research has also 
found that applicant reactions to selection procedures can adversely influence the self-perceptions of women believed to have been preferentially hired. "Being hired preferentially lead to lowered self-perceptions of competence and lowered task performance, but such effects seem to occur for women and not for men" (Ryan \& Ployhart, 2000: 594). Research conducted by Heilman, Rivero and Brett (1991: 104) on preferential selection reported that "women who believe themselves to have been preferentially selected on the basis of their sex for managerial or other male sex-typed positions often will shy away from the very activities and projects that will give them visibility and facilitate their advancement."

\subsubsection{Privacy concerns}

The past two decades have given rise to theoretical and empirical advances in privacy research in organizational contexts. Models of organizational privacy by Stone and colleagues (Stone \& Stone, 1990; Stone \& Stone, 2007; Stone \& Stone-Romero, 1998) discuss factors affecting individual regulation of privacy-related information. Among these factors are information factors. These include: the organization's purpose for information collection, the type of information that is to be collected from the individual, the targets of information disclosure, the extent to which the information provided is verifiable, the procedures used to collect information, and the transparency, reliability, and validity of those procedures.

Empirical research conducted by Stone-Romero, Stone, and Hyatt (2003) suggests that applicants perceive the application blank, the interview, and the work sample as selection procedures with relatively low invasiveness. On the other hand, lie detector and drug tests as well as medical examinations were perceived by applicants as selection procedures with relatively high invasiveness. Furthermore, perceived invasiveness was positively associated with the degree to which applicants believed a selection procedure discredited applicants, probed the bodies and minds of applicants, implied distrust of applicants, resulted in uneasy applicant feelings, and had the potential to reveal negative information about the applicant. Additional analysis revealed that perceived invasiveness was negatively associated with the amount of experience applicants had with certain selection procedures, the extent to which certain selection procedures have allowed applicants to form positive impressions, and the frequency with which applicants believe the organization uses a selection procedure.

Stone and Kotch (1989) used a sample of 73 manufacturing employees to investigate the effects of hypothetical drug testing policies. These researchers found that negative employee reactions to drug testing policies were influenced by the extent of the advance notice given for such policies to take effect, and whether or not the organization responded to detected drug use through employee assistance programs rather than through termination of employment. Eddy, Stone, and Stone-Romero (1999) examined effects of the implementation of information management policies on employees within an organization in the process of implementing a human resource information system. The researchers found that information management policies were perceived to be most invasive and most unfair when applicants did not have the ability to authorize the release of information which is subsequently released to a source outside the organization.

Harris, Van Hoye, and Lievens (2003) examined the relationship between applicant privacy perceptions and the submission of employment-related information via the Internet. Using undergraduate students from the United States (US) and Belgium, these researchers found that within the US sample, respondents' reluctance to submit employment-related information via the Internet was positively associated with concerns regarding the likelihood that technical difficulties would occur. The reluctance of respondents within the Belgian sample to submit employment-related information over the Internet was positively associated with the concern that the information would 'fall into the wrong hands. Overall, respondents with a greater self-reported knowledge of the Internet were less concerned with such information falling into the wrong hands.

Bauer et al. (2006) conducted both laboratory and field studies that examined the effects of information privacy concerns and computer experience on applicant reactions to Internet-based selection procedures. It was found that the association between applicants' information privacy concerns and test-taking motivation, organizational attraction, and organizational intentions were mediated by procedural justice in both laboratory and field samples. In the field study, applicant experience with computers was found to moderate the association between procedural justice and test-taking motivation and organizational intentions while no moderating effects were found in the laboratory study.

\subsubsection{Individual differences and emerging technology}

Applicant reactions research is emerging with respect to new selection technology (see Anderson, 2003 for a review). Using a sample of undergraduate students enrolled in a Spanish university, Salgado and Moscoso (2003), examined perceptions and reactions to the use of a paper-and-pencil based version of a Big Five personality questionnaire versus an Internet-based version of the same test. Salgado and Moscoso (2003) found that participants rated the Internet-based version of the Big Five personality as more comfortable and less intimidating than the paper-and-pencil version. Weichmann and Ryan (2003) found that participant perceptions of a computerized selection process are positively associated with applicant test-taking efficacy and computer experience, and negatively associated with computer anxiety. Exploratory research conducted by McManus and Ferguson (2003) encourages future research to examine the role of individual differences in applicant reactions to both online and paper-and-pencil based versions of selection procedures. Scholars also encourage future research to examine individual and cultural differences among applicants and their effects on selection processes and outcomes (Hough, Oswald, \& Ployhart, 2001; Stone-Romero, 2005).

In summary, applicants react favorably and perceive selection processes as fair when they are perceived to be related to the job; they are given explanations as to how the tools are related to future job performance; they are given an opportunity to perform and provide input into the decisions, and when the tools and procedures are consistently administered. Applicants also prefer processes that allow for two-way communication, and the timely provision of feedback. Applicants react negatively to organizations when recruiters are perceived as misleading, and when they are not treated with sincerity. Research remains mixed 
concerning the influence of applicant (i.e., test-taker) attitudes on their subsequent reactions to selection procedures. However, some research suggests that applicant reactions may be influenced by test-taking motivation, self-perceptions, and the extent to which a selection procedure invades privacy.

Chan and Schmitt (2004) note that one of the most important but neglected areas of applicant reactions research concerns if and how reactions change over time. In the next section, we develop a model of applicant reactions that draws upon organizational justice and organizational trust research and delineates how justice and trust interact over the course of a selection process.

\section{An integrative model of justice and trust perspectives on applicant reactions to selection procedures}

While extant research has primarily examined applicant reactions to selection procedures through an organizational justice lens, we suggest that by incorporating a trust perspective researchers can gain a more comprehensive understanding of the psychological mechanisms underlying the course of a selection process. Our integrated model therefore delineates the dynamic relationship between organizational justice and trust across different stages of the selection process. This model is depicted in Fig. 2.

Specifically, this model contributes to our understanding of applicant responses in three important ways. First, our model highlights that organizational justice perceptions are likely to be influenced by applicants' initial trust in the organization. The traditional view in the literature is that fairness perceptions are influenced by the procedural and distributive justice rules (Gilliland, 1993). Our model, however, extends current understanding by proposing that initial trust in the organization plays a key role in forming justice evaluations. In other words, we suggest that applicants' evaluations of fairness are heavily influenced by expectations or preconceptions applicants hold prior to the actual encounter with the organization. This proposition concurs with that of scholars who have noted the need to include applicants' early expectations in the study of applicants' reactions (Truxillo et al., 2004). Since trust entails positive expectations (as will be explained below), by integrating trust in the model, we are responsive to this call in the literature.

Second, our model suggests that initial trust will not only influence the evaluation of fairness but will also influence applicant reactions after justice perceptions are formed. Thus, while extant research has focused on the direct effects of justice perceptions on applicant responses, our model suggests that initial trust in the organization will also moderate the relationship between justice perceptions and several applicant responses. Finally, consistent with research that attests to the strong impact that justice perceptions have on trust formation (e.g., Brockner \& Siegel, 1996; Lewicki et al., 2005; Tzafrir, Harel, Baruch, \& Dolan, 2004), and the view of trust as constantly evolving and evaluated by organizational members (Robinson, Dirks, \& Ozcelik, 2004), our model highlights the impact of justice perceptions on subsequent trust in the organization.

In sum, by integrating an organizational trust perspective to the study of applicant reactions, we shed new light on important underlying processes that may play an important role in shaping applicant reactions. In what follows, we will define the concept of trust, and present the integrative model of applicant reactions that we have developed and the propositions derived from it.

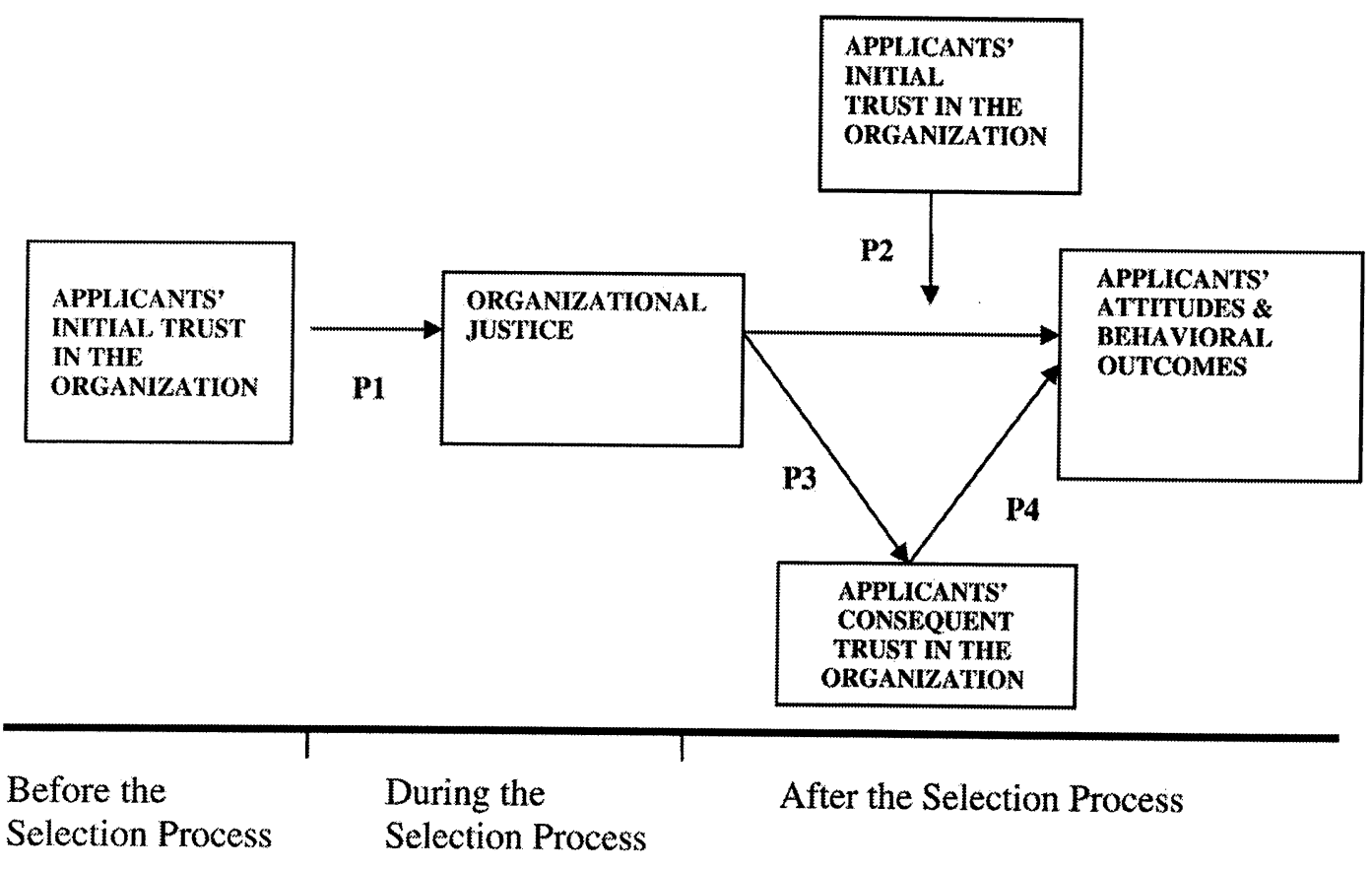

Fig. 2. Applicant reactions to selection procedures: An integrative model of justice and trust perspectives. 


\subsection{Trust and applicant reactions}

Multiple definitions of trust have been offered across different disciplines. While there is no single unanimously accepted definition of trust, a convergence around the central features that define trust seems to materialize among trust scholars. A review of cross-disciplinary research on trust suggests that there is an agreement that trust is 'the willingness to be vulnerable based upon positive expectations of the intentions or behavior of the other party' (Rousseau, Sitkin, Burt, \& Camerer, 1998). Trust has generally been conceived as something good - individuals' trust in the organization and its leaders has been found to be of critical benefit for organizations including organizational commitment, organizational citizenship behavior (e.g., Dirks \& Ferrin, 2001), team performance (Dirks, 2000), and organizational performance (Davis, Schoorman, Mayer, \& Tan, 2000). In addition, research suggests that firms that establish trust in them can inoculate individuals from the negative effects of future unfavorable outcomes (Robinson, 1996).

Research suggests that trust evolves through the social exchange between two parties (Whitener, Brodt, Korsgaard, \& Werner, 1998). Social exchange theory is concerned with the general processes and principles that govern the exchange of valued psychological, social and material commodities (McClintock, Kramer, \& Keil, 1984). Like economic exchange, social exchange generates an expectation of some future return for contributions; however, unlike economic exchange, the exact nature of the exchange is unspecified (McClintock et al., 1984). A basic tenet of social exchange theory is that actors within a relationship are compelled to reciprocate commodities because they are motivated to maintain a balance between inputs and outputs and to stay out of debt in social transactions (McClintock et al., 1984). The social exchange framework has been widely used in the literature to examine an individual's exchange with an organization because their exchanges encompass not only material but also psychological and social commodities (e.g., Marcus \& House, 1973; Whitener et al., 1998). Because this type of exchange relies on an implicit understanding that the actions of one individual are dependent on the actions of another (Molm, 1994, 2000, 2003), trust is necessary for the initiation of a social exchange and for its maintenance.

Applying this framework to the context of applicant reactions research, a social exchange relationship would begin with an applicant initiating an exchange by applying to an organization. By doing so, the applicant places an initial trust in the organization. In other words, when applying for a job, applicants expose themselves to enhanced vulnerability based upon positive expectations they hold about the future behavior of the organization (via its representatives). For example, because applicants often have to waive certain rights held prior to the application for employment with respect to reference information from prior employers (Woska, 2007), they have to trust the organization that sensitive information would be kept confidential or would not be unnecessarily shared with other organizational members.

\subsection{The effect of initial trust on applicant reactions}

How is initial trust in the organization likely to affect applicants? We suggest that initial trust is likely to affect applicant perceptions, attitudes and behavior both during and after the selection process.

\subsubsection{The effect of initial trust during the selection process}

Initial trust is not based on any kind of previous direct experience with, or firsthand knowledge of, the organization (McKnight, Cummings, \& Chervany, 1998). Instead, it is based on the individual's disposition to trust and on information provided by a third party (e.g., a friend who works in the organization), or other cues (e.g., the company's website or in the press). Interestingly, although some trust theorists had suggested that initial trust is typically low and then develops gradually over time, both surveys and experimental studies have shown that, in fact, initial trust is often quite high (e.g., Berg, Dickhaut, \& McCabe, 1995).

As mentioned, high initial trust implies that applicants are willing to be vulnerable based on favorable expectations they hold from the organization in terms of how they will be treated by it. Research suggests that prior expectations bias individuals' perceptions - individuals' preconceived notions tend to filter the information to which they pay attention, such that evidence contrary to one's beliefs is often ignored (Fiske \& Taylor 1991). Trust scholars maintain that attentional cognitive processes sustain initial trust precisely in this manner (Mcknight et al., 1998). An applicant who expects to be treated favorably during a selection process may likely overlook cues that may be indicative of low organizational trustworthiness. Consistent with this confirmation bias, Bell, Wiechmann and Ryan (2006) reported that applicants' expectations of justice were related to their perceptions of justice in the testing process. Along similar lines, Robinson (1996) found that employees with high initial trust, in contrast to those with low initial trust, were less likely to perceive a contract breach by his or her employer. Based on this literature, we contend that the higher applicants' initial trust in the organization, the more favorable their justice perceptions of the selection system will be. Stated as a proposition:

Proposition 1. There will be a positive relationship between applicants' initial trust in the organization and organizational justice.

\subsubsection{The effect of initial trust following the selection process}

Research suggests that once justice perceptions are formed, they are likely to affect a range of individual outcomes. It has been suggested, for example, that evaluations of fairness will have an impact on self-perceptions (e.g., self-esteem and self-efficacy), attitudes toward the organization, and the work behavior of the person who is hired (Gilliland, 1993). While some empirical evidence supports the direct impact of fairness perceptions on applicant outcomes (e.g., Ployhart et al., 1999; Bauer et al., 1998; Macan et al., 1994), these results have not been consistent (e.g., Bauer, Campion, Paronto, 2002). 
Lack of consistent findings about the direct effect of justice perceptions on individual outcomes may be suggestive of missing moderators. In other words, there may be variables that contribute or mitigate applicant responses to fairness perceptions that are not yet identified in the literature. We suggest that initial trust in the organization may play precisely this role. Previous research shows that initial trust exacerbates the negative response to unfavorable events. Brockner, Tyler and Cooper-Schneider (1992), for example, found that the commitment levels of those who had the highest commitment dropped most significantly after they discovered that authority was unfair in their layoff policies. Along similar lines, Robinson et al., (2004) found that prior trust enhanced the negative response to a breach of trust. Together, these findings are consistent with the view that individuals generally respond negatively to the disconfirmation of expectancies, especially to negative discrepancies (Brockner et al., 2001).

Based on this rationale, we propose that negative responses to organizational injustice will be stronger among those applicants whose initial trust in the organization was higher. In other words, applicants who previously held positive expectations from the organization and were therefore willing to be vulnerable, will respond especially negatively when they perceive to be treated unfairly by the organization. Applicants whose initial trust in the organization was low, on the other hand, will be less disappointed and therefore will not respond as negatively to perceptions of organizational injustice. Stated as a proposition:

Proposition 2. Initial trust will moderate the negative relationship between organizational justice and applicants reactions (attitudinal and behavioral), such that applicants with higher initial trust will experience more negative reactions to low organizational justice than
applicants with lower initial trust.

\subsubsection{The effect of organizational justice on consequent trust in the organization}

Our model also suggests that perceptions of justice in the selection process will affect consequent trust in the organization. The idea of trust as an outcome of justice has been well documented by empirical research (e.g., Aryee, Budhwar, and Chen, 2002; Brockner and Siegel, 1996; Lewicki et al., 2005). Numerous studies confirm that people's trust in other people and organizations grows as a result of fair treatment. In fact, as identified by Lewicki et al. (2005), the majority of research investigating the relationship between justice and trust falls into this category. Based on this literature, we propose the following:

Proposition 3. There will be a positive relationship between organizational justice perceptions in the selection process and consequent trust in the organization.

The importance of trust in the organization as an outcome of fairness becomes evident once we consider the potent consequences of trust. As mentioned earlier, trust in the organization and its leaders was found to influence critical outcomes including organizational commitment, organizational citizenship behavior (e.g., Dirks \& Ferrin, 2002), team performance (Dirks, 2000), and organizational performance (Davis et al., 2000). Moreover, research conducted by Aryee, Budhwar, and Chen (2002) found that organizational trust mediated the relationship between justice (i.e., distributive, procedural, and interactional) and employee outcomes such as job satisfaction, turnover intentions, and organizational commitment.

Based on this extensive literature, our model suggests that the level of consequent trust in the organization mediates the relationship between organizational justice and applicant attitudes and behavioral outcomes. For example, an applicant who witnesses inconsistent administration of a selection test among applicants may form low justice perceptions that will result in diminished organizational trust, which, in turn may translate into outcomes such as intentions not to recommend the organization to other prospective applicants, or diminished citizenship behavior. Stated as a proposition:

Proposition 4. Consequent trust in the organization will partially mediate the relationship between organizational justice perceptions and applicant reactions (attitudinal and behavioral).

\section{Avenues for future research}

Our review of extant literature and the integrated model developed in this paper shed light on several promising avenues for future research. First, we encourage scholars to empirically investigate the propositions derived from the integrated model in this paper. It will be intriguing to discover whether initial trust in the organization indeed plays an important role in evaluating fairness as well as in influencing applicants' attitudes and behavior. Second, future research may benefit from examining the issue of justice/injustice asymmetry. It has been noted by Gilliland and Chan (2001) that a recent development in the definition of organizational justice constructs has been the differentiation of justice and injustice. Specifically, some researchers have questioned whether justice and injustice represent symmetric ends of a continuum. Gilliland, Benson, and Schepers (1998) note that some organizational outcomes are more heavily influenced by what organizations do wrong (violations) than what they do right (nonviolations). To the extent that justice and injustice are ends of a continuum, trust may be most significant when violations take place. Third, we concur with Chan and Schmitt's (2004) concern that causal relations have been difficult to establish in applicant reactions research due to an over-reliance on correlational studies and call for more experimental studies to establish causal linkages involving applicant reactions. Fourth, future research should be directed at examining new testing technology. Computer-based and internet-based selection testing is gaining popularity among organizations due to their cost and administrative advantages (Bauer, Truxillo, Paronto, Weekley, \& Campion, 2004; Chan \& Schmitt, 2004). In an interview context, research thus far has demonstrated that applicants react more favorably to face-to-face interviews than telephone and video conferencing interviews (Chapman \& Rowe, 2002; Chapman, Uggerslev, \& Webster, 2003; Kroeck \& Magnusen, 1997; Silvester, Anderson, Haddleton, Cunningham-Snell, \& Gibb, 2000; Strauss, Miles \& Levesque, 2001). An increasing amount of applicant reactions research needs to be examined in the context of this emerging selection technology. It will be of 
importance for researchers to examine the extent to which this technology influences applicant reactions to selection procedures. Finally, further examination of the role of culture in applicant reactions to selection processes is required (Steiner \& Gilliland, 2001). The proposed model may lend itself to such cross-cultural research through the identification of individual beliefs prior to the selection process. As noted above by Morris and Leung (2000), beliefs may serve as a filter through which cross-cultural values may be interpreted. As a result, cross-cultural research may confirm the role of different cultural dimensions in determining the importance of various rules of organizational justice (Steiner \& Gilliland, 2001: 134). It is also possible that applicants' initial trust in organizations differ across cultures.

\section{Conclusion}

The goals of this paper were to review extant applicant reactions research and to provide a new theoretical framework that integrates organizational justice and trust to better understand applicant responses over time. The model we developed highlights that trust can play a critical role in applicants' responses over the course of a selection process. First, the model acknowledges that applicants approach the selection process with a given level of initial trust in the organization. This initial trust, in turn, is likely to significantly influence their experience and responses to the selection process. In other words, applicant reactions are as heavily influenced by preconceptions they hold prior to the encounter with the organization as they are by the characteristics of the selection procedures themselves. Specifically, initial trust is likely to affect applicant perceptions of the fairness of the procedures the higher their initial trust in the organization the more likely they are to perceive high organizational justice.

Second, our model offers a counterintuitive contention - high initial trust in the organization can be a mixed blessing. On the one hand, as mentioned, individuals with high initial trust are more likely to overlook minor cues during the selection process that disconfirm their preconceptions and are therefore more likely to perceive high organizational justice. On the other hand, if there are major cues that indicate that the organization is not treating applicants fairly, individuals with high initial trust are likely to be more disappointed and therefore respond more negatively to perceptions of low justice than individuals with low initial trust. This interesting dynamic underscores the importance of consistently maintaining a trustworthy image of the organization as unfulfilled expectations may backfire.

Finally, in line with extant research on HR activities and trust, our model views trust as both an important determinant of applicant reactions, as well as a critical outcome of the selection process. We suggest that while applicants' first encounter with the organization entails some level of trust, this level is likely to be influenced by the selection process itself and critically influence consequent attitudes and behavior.

\section{References}

Adams, J. S. (1965). Inequity in social exchange. In L. Berkowitz (Ed.), Advances in experimental social psychology, Vol. 2. (pp. 267-299)New York: Academic Press. Ambrose, M. L. (2000). Drug testing and procedural fairness: The influence of situational variables. Social Justice Research, 13, 25-40.

Anderson, N. (2003). Applicant and recruiter reactions to new technology in selection: A critical review and agenda for future research. International Journal of Selection and Assessment, 11, 121-136.

Anderson, N., Born, M., \& Cunningham-Snell, N. (2001). Recruitment and selection: Applicant perspectives and outcomes. In N. Anderson, D. S. Ones, H. K. Sinangil, \& C. Viswesvaran (Eds.), Handbook of industrial, work, and organizational psychology (pp. 200-218).

Arvey, R. D., \& Sackett, P. R. (1993). Fairness in selection: Current developments and perspectives. In N. Schmitt, \& W. C. Borman (Eds.), Personnel selection in organizations (pp. 171-202). San Francisco: Jossey-Bass.

Arvey, R. D., Strickland, W., Drauden, G., \& Clessen, M. (1990). Motivational components of test taking. Personnel Psychology, 43, 695-716.

Aryee, S., Budhwar, P. S., \& Chen, Z. X. (2002). Trust as a mediator of the relationship between organizational justice and work outcomes: Test of a social exchange model. Journal of Organizational Behavior, 23, 267-286.

Barber, A. E. (1998). Recruiting employees. Thousand Oaks, CA: Sage.

Bauer, T. N., Campion, M. A., \& Paronto, M. E. (2002). Selection fairness information and applicant reactions: A longitudinal field study. Journal of Applied Psychology, 87, 1020-1031.

Bauer, T. N., Maertz, C. P., Dolen, M. R., \& Campion, M. A. (1998). Longitudinal assessment of applicant reactions to employment testing and test outcome feedback. Journal of Applied Psychology, 83, 892-903.

Bauer, T. N., Truxillo, D. M., Paronto, M. E., Weekley, J. A., \& Campion, M. A. (2004). Applicant reactions to different selection technology: Face-to-face, interactive voice response, and computer-assisted telephone screening interviews. International Journal of Selection and Assessment, 12, 135-148.

Bauer, T. N., Truxillo, D. M., Sanchez, R., Craig, J., Ferrara, P., \& Campion, M. A. (2001). Development of the Selection Procedural Justice Scale (SPJS). Personnel Psychology, 83, 892-903.

Bauer, T. N., Truxillo, D. M., Tucker, J. S., Weathers, V., Bertolino, M., Erdogan, B., \& Campion, M. A. (2006). Journal of Management, 32, 601-621. Bell, B. S., Wiechmann, D., \& Ryan, A. M. (2006). Consequences of organizational justice expectations in a selection system. Journal of Applied Psychology, 91,
455-466.

Berg, J., Dickhaut, J., \& McCabe, K. (1995). Trust, reciprocity and social history. Games and Economic Behavior, 10, $122-142$.

Bierhoff, H. W., Buck, E., \& Klein, R. (1986). Social context and perceived justice. In H. W. Bierhoff, R. L. Cohen, \& J. Greenberg (Eds.), Justice in social relations (pp. 165-186). Plenum Press: New York.

Bies, R. J., \& Moag, J. S. (1986). Interactional justice: Communication criteria of fairness. Research On Negotiation In Organizations, 1, $43-55$.

Bies, R. J., \& Shapiro, D. L. (1988). Voice and justification: Their influence on procedural fairness judgments. Academy of Management Journal, 31, 676-685.

Brockner, J., Ackerman, G., Greenberg, J., Gelfand, M., Francesco, A., Chen, Z., Leung, K., Bierbrauer, G., Gomez, C. B., Kirkman, B. L., \& Shapiro, D. L. (2001). 'Culture and procedural justice: The influence of power distance on reactions to voice'. Journal of Experimental Social Psychology, 37(4), 300-315.

Brockner, J., \& Siegel, P. (1996). Understanding the interaction between procedural and distributive justice: The role of trust. In R. Kramer, \& T. Tyler (Eds.), Trust in organizations: Frontiers of theory and research (pp. 390-413). Thousand Oaks, CA: Sage.

Brockner, J., Tyler, T. R., \& Cooper-Schneider, R. (1992). The influence of prior commitment to an institution on reactions to perceived unfairness: The higher they are, the harder they fall. Administrative Science Quarterly, Vol. 37, 241-261.

Carless, S. A. (2006). Applicant reactions to multiple selection procedures for the police force. Applied Psychology: An International Review, $55,145-167$. Chambers, B. A. (2002). Applicant reactions and their consequences: Review, advice and recommendations for future research. International Journal of Management
Reviews, 4, 317-333.

Chan, D. (1997). Racial subgroup differences in predictive validity perceptions on personality and cognitive ability tests. Journal of Applied Psychology, 82, 311-320. 
Chan, D., \& Schmitt, N. (1997). Video-based versus paper-and-pencil method of assessment in situational judgment tests: Subgroup differences in test performance and face validity perceptions. Journal of Applied Psychology, 82, 143-159. Chan, D., \& Schmitt, N. (2004). An agenda for future research on applicant reactions to selection procedures: A construct-oriented approach. International Journal of
Selection and Assessment, 12, 9-23.

Chan, D., Schmitt, N., DeShon, R. P., Clause, C. S., \& Delbridge, K. (1997). Reactions to cognitive ability tests: The relationships between race, test performance, face validity perceptions, and test-taking motivation. Journal of Applied Psychology, 82, 300-310.

Chan, D., Schmitt, N., Sacco, J. M., \& DeShon, R. P. (1998). Understanding pre-test and post-test reactions to cognitive ability and personality tests. Journal of Applied Psychology, 83, 471-485. Chapman, D. S., \& Rowe, P. M. (2002). The influence of videoconference technology and interview structure on the recruiting function of the employment interview:
A field experiment. International Journal of Selection and Assessment, 10, 185-197. Chapman, D. S., Uggerslev, K. L., \& Webster, J. (2003). Applicant reactions to face-to-face and technology-mediated interviews: A field investigation. Journal of
Applied Psychology, 88, 944-953.

Colquitt, J. A., Conlon, D. E., Wesson, M. J., Porter, C. O. L. H., \& Yee Ng, K. (2001). Justice at the millennium: A meta-analytic review of 25 years of organizational justice research. Journal of Applied Psychology, 86, 425-445.

Cropanzano, R., \& Konovsky, M. A. (1995). Resolving the justice dilemma by improving the outcomes: The case of employee drug screening. Journal of Business and Psychology, 10, 221-243.

Cropanzano, R., \& Wright, T. A. (2003). Procedural justice and organizational staffing: A tale of two paradigms. Human Resource Management Review, 13, 7-39.

Cunningham, M. R. (1989). Test-taking motivations and outcomes on a standardized measure of on-the-job integrity. Journal of Business and Psychology, 4, 119-127. Davis, J. H., Schoorman, F. D., Mayer, R. C., \& Tan, H. H. (2000). The trusted general manager and business unit performance: Empirical evidence of a competitive
advantage. Strategic Management Journal, 21, 563-576.

Deutsch, M. (1975). Equity, equality, and need: What determines which value will be used as the basis of distributive justice? Journal of Social Issues, 31, 137-149.

Dirks, K. T. (2000). Trust in leadership and team performance: Evidence from NCAA basketball. Journal of Applied Psychology, 85, 1004-1012.

Dirks, K. T., \& Ferrin, D. L. (2001). The role of trust in organizational settings. Organization Science, 12, 450-467.

Dirks, K. T., \& Ferrin, D. L. (2002). Trust in leadership: Meta-analytic findings and implications for research and practice. Journal of Applied Psychology, 87, 611-628.

Eddy, E. R., Stone, D. L., \& Stone-Romero, E. F. (1999). The effects of information management policies on reactions to human resource information systems: An integration of privacy and procedural justice perspectives. Personnel Psychology, 52, 335-358.

Elkin, T. J., \& Phillip, J. S. (2000). Job context, selection decision outcome, and the perceived fairness of selection tests: Biodata as an illustrative case. Journal of Applied Psychology, 85, 479-484.

Fiske, S. T., \& Taylor, S. E. (1991). Social cognition. New York: McGraw-Hill, Inc.

Folger, R., \& Cropanzano, R. (1998). Organizational justice and human resource management. Thousand Oaks, CA: Sage.

Folger, R., \& Greenberg, J. (1985). Procedural justice: An interpretive analysis of personnel systems. Research in Personnel and Human Resources Management, 3, $141-183$.

Fulk, J., Brief, A. P., \& Barr, S. H. (1985). Journal of Business Research, 13(4), 301-313.

Gatewood, R. D., \& Field, H. S. (1998). Human resource selection (4th ed.). Fort Worth, TX: Harcourt Brace.

Gilliland, S. W. (1993). The perceived fairness of selection systems: An organizational justice perspective. Academy of Management Review, 18, 694-734.

Gilliland, S. W. (1994). Effects of procedural and distributive justice on reactions to a selection system. Journal of Applied Psychology, 79, 691-701.

Gilliland, S. W. (1995). Fairness from the applicant's perspective: Reactions to employee selection procedures. International Journal of Selection and Assessment, 3, 11-19. Gilliland, S. W., \& Honig, H. (1994). The perceived fairness of employee selection systems as a predictor of attitudes and self-concept. Personnel Psychology, 47,
715-738.

Gilliland, S. W., Benson, L., III, \& Schepers, D. H. (1998). A rejection threshold in justice evaluations: Effects on judgment and decision making. Organizational Behavior and Human Decision Processes, 76, 113-131.

Gilliland, S. W., \& Chan, D. (2001). Justice in organizations: Theory, methods, and applications. In N. Anderson, D. S. Ones, H. K. Sinangil, \& C. Viswesvaran (Eds.) Handbook of industrial, work, and organizational psychology (pp. 143-165). Thousand Oaks, CA: Sage. Gilliland, S. W., Groth, M., Baker, B., Dew, A. F., Polly, L. M., \& Langdon, J. (2001). Improving applicants' reactions to rejection letters: An application of fairness theory.
Personnel Psychology, 54, 669-703.

Gilliland, S. W., \& Hale, J. M. S. (2005). How can justice be used to improve employee selection practices? In J. Greenberg, \& J. A. Colquitt (Eds.), Handbook of organizational justice (pp. 411-438). Mahwah, New Jersey: Lawrence Erlbaum Associates.

Harris, L. (2000). Procedural justice and perceptions of fairness in selection practice. International Journal of Selection and Assessment, 8, $148-157$. Harris, M. M., \& Fink, L. S. (1987). A field study of applicant reactions to employment opportunities: Does the recruiter make a difference? Personnel Psychology, 40,
765-784.

Harris, M. M., Van Hoye, G., \& Lievens, F. (2003). Privacy and attitudes toward internet-based selection systems: A cross-cultural comparison. International Journal of Selection and Assessment, 11, 230-236.

Hausknecht, J. P., Day, D. V., \& Thomas, S. C. (2004). Applicant reactions to selection procedures: An updated model and meta-analysis. Personnel Psychology, 57, 639-683.

Heilman, M. E., Rivero, J. C., \& Brett, J. F. (1991). Skirting the competency issue: Effects of sex-based preferential selection on task choices of men and women. Journal of Applied Psychology, 76, 99-105.

Homans, G. C. (1961). Social behavior: It's elementary forms. New York: Harcourt, Brace, and World.

Horvath, M., Ryan, A. M., \& Steirwalt, S. L. (2000). The influence of explanations for selection test use, outcome favorability, and self-efficacy on test-taker perceptions. Organizational Behavior and Human Decision Processes, 83, 310-330.

Hough, L. M., Oswald, F. L., \& Ployhart, R. E. (2001). Determinants, detection, and amelioration of adverse impact in personnel selection procedures: Issues, evidence, and lessons learned. International Journal of Selection and Assessment, 9, 152-194.

Kohn, L. S., \& Dipboye, R. L. (1998). The effects of interview structure on recruiting outcomes. Journal of Applied Social Psychology, 28, 821-843.

Kravitz, D. A., Stinson, V., \& Chavez, T. L. (1996). Evaluations of test used for making selection and promotion decisions. International Journal of Selection and Assessment, 4, 24-34.

Kroeck, K. G., \& Magnussen, K. O. (1997). Employer and job candidate reactions to videoconference job interviewing. International Journal of Selection and Assessment, 5, 137-142.

Latham, G. P., \& Finnegan, B. J. (1993). Perceived practicality of unstructured, patterned, and situational interviews. In H. Schuler, J. L. Farr, \& M. Smith (Eds.), Personnel selection and assessment: Individual and organizational perspectives (pp. 41-55). Hillsdale, NJ: Erlbaum.

Leventhal, G. S. (1980). What should be done with equity theory? In K. J. Gergen, M. S. Greenberg, \& R. H. Willis (Eds.), Social exchange: Advances in theory and research (pp. 27-55). Hillsdale, NJ: Erlbaum.

Lewicki, R. J., Wiethoff, C., \& Tomlinson, E. C. (2005). What is the role of trust in organizational justice? In J. Greenberg, \& J. A. Colquitt (Eds.), Handbook of organizational justice (pp. 247-270). Mahwah, New Jersey: Lawrence Erlbaum Associates.

Liden, R. C., \& Parsons, C. K. (1986). A field study of job applicant interview perceptions, alternative opportunities, and demographic characteristics. Personnel Psychology, 39, 109-122.

Lievens, F., De Corte, W., \& Brysse, K. (2003). Applicant perceptions of selection procedures: The role of selection information, belief in tests, and comparative anxiety. International Journal of Selection and Assessment, 11, 67-77.

Lounsbury, J. W., Bobrow, W., \& Jensen, J. B. (1989). Attitudes toward employment testing: Scale development, correlates, and 'known group' validation. Professional Psychology: Research and Practice, 20, 340-349.

Macan, T. H., Avedon, M. J., Paese, M., \& Smith, D. E. (1994). The effects of applicants' reactions to cognitive ability tests and an assessment centre. Personnel Psychology, 47, 715-738. 
Marcus, P. M., \& House, J. S. (1973). Exchange between superiors and subordinates in large organizations. Administrative Science Quarterly, $18,209-222$.

McEnrue, M. P. (1989). The perceived fairness of managerial promotion practices. Human Relations, 42, 815-827.

McClintock, C. G., Kramer, R. M., \& Keil, L. J. (1984). Equity and social exchange in human relationships. Advances in Experimental Social Psychology, $17,183-288$. 472-490. McManus, M. A., \& Ferguson, M. W. (2003). Biodata, personality, and demographic differences of recruits from three sources. International Journal of Selection and
Assessment, 11, 175-183.

McMillan-Capehart, A., \& Orlando, R. (2005). Organizational justice and perceived fairness of hiring decisions related to race and gender: Affirmative action reactions. Equal Opportunties International, 24, 44-57.

Molm, L. D. (1994). Dependence and risk: Transforming the structure of social exchange. Social Psychology Quarterly, 57, $163-176$.

Molm, L. D. (2000). Theories of social exchange and exchange networks. In G. Ritzer, \& B. Smart (Eds.), Handbook of social theory (pp. 260-272). CA: Thousand Oaks.

Molm, L. D. (2003). Theoretical comparisons of forms of exchange. Sociological Theory, 21, 1-17. Morris, W. M., \& Leung, K. (2000). Justice for all? Progress in research on cultural variation in the psychology of distributive and procedural justice. Applied
Psychology: An International Review, 49, 100-132.

Motowidlo, S. J., Dunnette, M. D., \& Carter, G. W. (1990). An alternative selection procedure: The low-fidelity simulation. Journal of Applied Psychology, $75,640-647$.

Murphy, K. R., Thornton, G. C., \& Prue, K. (1991). Influence of job characteristics on the acceptability of employee drug testing. Journal of Applied Psychology, 76,
447-453. Ployhart, R. E., McFarland, L. A., \& Ryan, A. M. (2003). Examining applicants' attributions for withdrawal from a selection procedure. Journal of Applied Social
Psychology, 32, 2228-2252.

Ployhart, R. E., \& Ryan, A. M. (1997). Toward and explanation of applicant reactions: An examination of organization justice and attribution frameworks. Organizational Behavior and Human Decision Processes, 72, 308-335.

Ployhart, R. E., Ryan, A. M., \& Bennett, M. (1999). Explanations for selection decisions: Applicants' reactions to informational and sensitivity features of explanations. Journal of Applied Psychology, 84, 87-106.

Robertson, I. T., Iles, P. A., Gratton, L., \& Sharpley, D. (1991). The impact of personnel selection and assessment methods on candidates. Human Relations, 44, 963-982.

Robinson, S. L. (1996). Trust and breach of the psychological contract. Administrative Science Quarterly, 41, 574-599. Robinson, S. L., Dirks, K. T., \& Ozcelik, H. (2004). 'Untangling the knot of trust and betrayal'. In Roderick M. Kramer, \& Karen S. Cook (Eds.), Trust and distrust in
organizations: Dilemmas and approaches New York: Russell Sage.

Rousseau, D. M., Sitkin, S. B., Burt, R. S., \& Camerer, C. (1998). Not so different after all: A cross-discipline view of trust. Academy of Management Review, $23,393-404$.

Rosse, J. G., Miller, J. L., \& Stecher, M. D. (1994). A field study of job applicants' reactions to personality and cognitive ability testing. Journal of Applied Psychology, 79 987-992.

Ryan, A. M., \& Chan, D. (1999). Perceptions of the EPPP: How do licensure candidates view the process? Professional Psychology, 30, 519-530.

Ryan, A. M., Greguras, G. J., \& Ployhart, R. E. (1996). Perceived job relatedness of physical ability testing for firefighters: Exploring variations in reactions. Human Performance, 9, 219-240. Ryan, A. M., \& Ployhart, R. E. (2000). Applicant perceptions of selection procedures and decisions: A critical review and agenda for the future. Journal of
Management, 26, 565-606.

Ryan, A., \& Tippins, N. (2004). Attracting and selecting: What psychological research tells us. Human Resource Management, 43(4), 305-319.

Rynes, S. L. (1993). Who's selecting whom? Effects of selection practices on applicant attitudes and behavior. In N. Schmitt, \& W. C. Borman (Eds.), Personnel selection in organizations (pp. 240-274). San Francisco: Jossey-Bass.

Rynes, S. L., Bretz,, R. D., Jr., \& Gerhart, B. (1991). The importance of recruitment in job choice: A different way of looking. Personnel Psychology, 44, 487-521. Saks, A. M., Leck, J. D., \& Saunders, D. M. (1995). Effects of application blanks and employment equity on applicant reactions and job pursuit intentions. Journal of
Organizational Behavior, 16, 415-430. Saks, A. M., \& McCarthy, J. M. (2006). Effects of discriminatory interview questions and gender on applicant reactions. Journal of Business and Psychology, 21,
175-191. Salgado, J. F., \& Moscoso, S. (2003). Internet-based personality testing: Equivalence of measures and assessees' perceptions and reactions. International Journal of
Selection and Assessment, 11, 194-205.

Schmit, M. J., \& Ryan, A. M. (1997). Applicant withdrawal: The role of test-taking attitudes and racial differences. Personnel Psychology, 50, 855-876.

Schmitt, N., \& Coyle, B. W. (1976). Applicant decisions in the employment interview. Journal of Applied Psychology, 61, 184-192.

Schmitt, N., \& Gilliland, S. W. (1992). Beyond differential prediction: Fairness in selection. In D. M. Saunders (Ed.), New approaches to employee management: Fairness in employee selection, Vol. 1. (pp. 21-46)Greenwich, CT: JAI Press.

Schuler, H. (1993). Is there a dilemma between validity and acceptance in the employment interview? In B. Nevo, \& R. S. Jager (Eds.), Educational and psychological testing: The test taker's outlook (pp. 239-250). Toronto, Canada: Hogrefe and Huber.

Silvester, J., Anderson, N., Haddleton, E., Cunningham-Snell, N., \& Gibb, A. (2000). A cross-modal comparison of telephone and face-to-face selection interviews in graduate recruitment. International Journal of Selection and Assessment, 8, 16-21.

Singer, M. (1990). Determinants of perceived fairness in selection practices: An organizational justice perspective. Genetic, Social, and General Psychology Monographs, 116, 477-494.

Smither, J. W., Reilly, R. R., Millsap, R. E., Pearlman, K., \& Stoffey, R. W. (1993). Applicant reactions to selection procedures. Personnel Psychology, 46, $49-76$. Steiner, D. D., \& Gilliland, S. W. (1996). Fairness reactions to personnel selection techniques in France and the United States. Journal of Applied Psychology, 81,
134-141.

Steiner, D. D., \& Gilliland, S. W. (2001). Procedural justice in personnel selection: International and cross-cultural perspectives. International Journal of Selection and Assessment, 9, 124-137.

Stone, D. L., \& Kotch, D. A. (1989). Individuals' attitudes toward organizational drug testing policies and practices. Journal of Applied Psychology, $74,518-521$.

Stone, E. F., \& Stone, D. L. (1990). Privacy in organizations: Theoretical issues, research findings, and protection mechanisms. Research in Personnel and Human Resource Management, 8, 349-411.

Stone, E. F., \& Stone, D. L. (2007). Current perspectives on privacy in organizations. In S. Gilliland, D. Steiner, \& D. Skarlicki (Eds.), Managing social and ethical issues in organizations (pp. 325-362). Greenwich, CT: Information Age Publishing.

Stone, D. L., \& Stone-Romero, E. F. (1998). A multiple stakeholder model of privacy in organizations. In M. Schminke (Ed.), Managerial ethics: Moral management of people and processes (pp. 35-59). Mahwah, NJ: Erlbaum.

Stone-Romero, E. F. (2005). The effects of e-HR system characteristics and culture on system acceptance and effectiveness. In H. G. Gueutal, \& D. L. Stone (Eds.), The brave new world of e-HR: Human resources management in the digital age (pp. 226-254). San Francisco, CA: Jossey-Bass.

Stone-Romero, E. F., Stone, D. L., \& Hyatt, D. (2003). Personnel selection procedures and invasion of privacy. Journal of Social Issues, 59, $343-368$.

Straus, S., Miles, J., \& Levesque, L. (2001). The effects of videoconference, telephone, and face-to-face media on interviewer and applicant judgments in employment interviews. Journal of Management, 27, 363-382.

Thibaut, J. W., \& Walker, L. (1975). Procedural justice: A psychological analysis. Hillsdale, NJ: Erlbaum. Thorsteinson, T. J., \& Ryan, A. M. (1997). The effect of selection ratio on perception of a selection test battery. International Journal of Selection and Assessment, 5,
159-165. Truxillo, D. M., Bauer, T. N., Campion, M. A., \& Paronto, M. E. (2002). Selection fairness information and applicant reactions: A longitudinal field study. Journal of
Applied Psychology, 87, 1020-1031.

Truxillo, D. M., Bauer, T. N., \& Sanchez, R. J. (2001). Multiple dimensions of procedural justice: Longitudinal effects on selection system fairness and test-taking selfefficacy. International Journal of Selection and Assessment, 9, 330-349. 

Truxillo, D. M., Steiner, D. D., \& Gilliland, S. W. (2004). The importance of organizational justice in personnel selection: Defining when selection fairness really
matters. International Journal of Selection and Assessment, 12, 39-53.

Tzafrir, S. S., Harel, G., Baruch, Y., \& Dolan, S. L. (2004). The consequences of emerging HRM (Practices for employees' trust in their managers. Personnel Review, 33 (6), 628-647.

Vianen, A., Taris, R., Scholten, E., \& Schinkel, S. (2004). Perceived fairness in personnel selection: Determinants and outcomes in different stages of the assessment procedure. International Journal of Selection and Assessment, 12, 149-159.

Viswesvaran, C., \& Ones, D. (2004). Importance of perceived personnel selection system fairness determinants: Relations with demographics, personality and job characteristics. International Journal of Selection and Assessment, 12, 172-186.

Wallace, J. C., Page, E. E., \& Lippstreu, M. (2006). Applicant reactions to pre-employment application blanks: A legal and procedural justice perspective. Journal of Business and Psychology, 20, 467-488.

Weichmann, D., \& Ryan, A. M. (2003). Reactions to computerized testing in selection contexts. International Journal of Selection and Assessment, 11, 215-229.

Werbel, J. D., \& Gilliland, S. W. (1999). Person-environment fit in the selection process. In G. Ferris (Ed.), Research in personnel and human resources management (pp. 209-243). Greenwich, CT: JAI.

Whitener, E. M., Brodt, S. E., Korsgaard, M. A., \& Werner, J. M. (1998). Managers as initiators of trust: An exchange relationship framework for understanding managerial trustworthy behavior. Academy of Management Review, 23, 513-530.

Woska, W. J. (2007). Legal issues for HR professionals: Reference checking/background investigations. Public Personnel Management, 36, 79-90. 